\title{
MORPHOLOGICAL AND STRUCTURAL CHANGES IN MYOCARDIUM, LIPID AND CARBOHYDRATE METABOLISM DURING DIFFERENT OUTCOMES OF CHRONIC HEART FAILURE IN PATIENTS WITH ISCHEMIC HEART DISEASE AND DIABETES MELLITUS TYPE II
}

\author{
Ekaterina Lipakova ${ }^{1}$ \\ ekaterinalipakova@gmail.com \\ Oleksandr Bilchenko ${ }^{1}$ \\ bilchenko.post@gmail.com \\ Olena Vysotska \\ Department of radio-electronic and biomedical computer-aided means and technologies \\ National Aerospace University - "Kharkiv Aviation Institute" \\ 17 Chkalov str., Kharkiv, Ukraine, 61070 \\ o.vysotska@khai.edu \\ Liubov Rysovana \\ Department of Medical Biophysics and Medical Informatics \\ Kharkiv National Medical University \\ 4 Nauki ave., Kharkiv, Ukraine, 61022 \\ rluba_24@ukr.net \\ ${ }^{1}$ Department of Internal Medicine, Nephrology and General Practice-Family Medicine \\ Kharkiv Medical Academy of Postgraduate Education \\ 58 Amosova str., Kharkiv, Ukraine, 61176
}

\footnotetext{
Abstract

Diabetes mellitus (DM) type II is an independent risk factor for cardiovascular system injury. To avoid progression of ischemic heart failure (IHF) it is important to find early signs of myocardial injury also as carbohydrate and lipid metabolism alterations.

The objective of the study: to establish features of structural and functional changes in myocardium, carbohydrate and lipid metabolism, in patients with different outcomes of chronic heart failure (CHF), caused by IHD and DM type II.

Material and methods. Examination of 100 patients who have CHF with IHF and DM type II was performed. Patients were divided in two groups, according to outcome: group I $(\mathrm{n}=66)$ - patients with favorable outcome, mean age 60.0 [55.8; 63.3] years, group II ( $\mathrm{n}=34)$ - unfavorable outcome of CHF, mean age 58.0 [55.0; 60.3] years.

We analysed complaints, cardiologycal anamnesis, cardiovascular risk factors, and physical examination data. Transthoracic echocardiography (TTE), carbohydrate and lipid panel were assessed to find out early specific signs of myocardial injury.

Results. We find out statistically significant associations between TTE results, lipid panel and CHF progression in study population.

Conclusions. Comparative analysis showed that degree of CHF in patients with IHD and DM type II that have preserved LV EF is associated with: duration of DM and $\mathrm{CHF}$, arterial hypertension (AH) level and degree of carbohydrate and lipid metabolism disturbances. Early TTE signs of unfavorable outcome are: increase of transmitral deceleration time (Dt), increase of mean PA pressure (PA MP) even in range lower the $20 \mathrm{mmHg}$.

Keywords: carbohydrate metabolism, lipid metabolism, myocardium morpho-functional state.
}

DOI: $10.21303 / 2504-5679.2020 .001139$

\section{Introduction}

There are 415 millions of patients around the world with diabetes mellitus (DM), $90 \%$ of them have DM type II [1]. Despite available scientific data about risk factors and DM-screening 
programs running, incidence of disease still increases. According to experts of International Diabetic Federation (IDF), in 2035 amount of people with DM type II will reach 592 million, this is approximately every tenth. This shows significance of ongoing study on genotype and phenotype of DM to individualise treatment for this kind of patients [2].

DM type II leads to micro- and macrovascular complications, and after that ischemic heart disease (IHD). Epidemiological data shows that cardiovascular complications are the main reason of morbidity and mortality among patients with DM (80\% of patients with DM type II mortality is connected to cardiovascular complications) [2]. Almost in $50 \%$ patients that have IHD, diagnosis of the DM type II, impaired glucose tolerance or impaired fasting glucose is found first time. According to this, American Heart Association (AHA) established presence of DM type II as equivalent of high risk of vascular complications, which is comparable with present cardiovascular diseases [3].

Nowadays there is a big interest in pathophysiological mechanisms, responsible for changes in cardiomyocites during DM type II [1]. Hyperglycemia leads to decrease in ability to resist oxidative stress by increase of glucose utilisation in citric acid pathway, increase in inflammatory response, that have influence on lipid metabolism and immune response, and leads to chronic inflammation in arterial vessel wall, endomyocardial fibrosis, necrosis and apoptosis of endothelial cells and cardyomiocytes $[4,5]$. This mechanisms combined with disorders of mineral metabolism, impairment of $\mathrm{Ca}^{2+}$ regulation of myofilament function, increase of active oxygen forms level, increased lipotoxycity, autonomic nervous system dysfunction, which one, according to progressive autonomic neuropathy, decrease vasodilative effect of sympathetic stimulation to coronary vessels resistance - thus accelerates coronary vessels calcification and appearance of CHF with DM type II $[6,7]$.

Despite present scientific data of DM type II influence on cardiovascular pathology, pathophysiology of myocardial ischemia during DM type II needs further investigation. One group of patients with DM type II have coronary artery disease that prevents normal blood flow to myocardium, another have microvascular changes without plaques, and absence or presence of endothelial dysfunction [8]. There is lack of data about main aspects of diabetic coronary microvascular dysfunction in structure of cardiovascular diseases, role of genetic types of ATP-dependent potassium channels that determine course of IHD by balancing coronary blood flow and cardiac performance $[9,10]$.

In modern era, it is important to study mechanisms of development and specific clinical signs of CHF on the early stage. Investigations should lead to development of new methods and materials of prophylactic and treatment.

The objective of the study: to highlight patterns of cardiac morphology and function, lipid and carbohydrate metabolism during different courses of heart failure in patients with IHF and DM type II.

\section{Material and methods}

We performed complex examination of 100 male patients with ischemic CHF with IHD and DM type II after in-hospital treatment. All patients signed an informed consent to participate in the study.

Examination was performed in therapy department of community-owned non-profit organization "City clinic of urgent and emergency medicine named after prof. A. I. Meschaninov" Kharkiv`s City Council, Ukraine, between February 2015 and January 2017.

Inclusion criteria: age between 50 and 70 years, CHF II functional class (FC) NYHA classification, LV EF $\geq 50 \%$ (according to criteria of European Society of Cardiology, 2016) [11], postinfraction cardiosclerosis with DM type II [12], glomerular filtration rate $\left(\geq 50 \mathrm{ml} / \mathrm{min} / 1.73 \mathrm{~m}^{2}\right)$, NT-proBNP $\geq 125 \mathrm{pg} / \mathrm{ml}$.

The authors declare that all the procedures and experiments of this study respect the ethical standards in the Helsinki Declaration of 1975, as revised in 2008(5), as well as the national law. Informed consent was obtained from all the patients included in the study. No funding for this study.

Exclusion criteria: age more then 70 years, resistive arterial hypertension (AH), secondary $\mathrm{AH}, \mathrm{LV} \mathrm{EF}<50 \%$, NT-proBNP $<125 \mathrm{pg} / \mathrm{ml}$, pulmonary artery hypertension, congenital and 
acquired heart diseases, IHD that requires administration of short-acting nitrates more than two times a week, non-coronary myocardial diseases, chronic kidney disease with glomerular filtration rate GFR $<50 \mathrm{ml} / \mathrm{min} / 1,73 \mathrm{~m}^{2}$, comorbidities: chronic obstructive pulmonary disease, bronchial asthma, anemia $\mathrm{Hb} \leq 90 \mathrm{~g} / 1$, acute and chronic inflammatory myocardial diseases, postoperative state, oncological diseases, inflammatory gastro-intestinal diseases, haemopoetic diseases, traumatic injuries, alcohol abuse.

Patients were divided in two groups according to outcome: group I $(n=66)$ - favourable outcome, mean age 60.0 [55.8; 63.3] years, group II ( $\mathrm{n}=34)$ - unfavourable outcome, mean age 58.0 $[55.0 ; 60.3]$ years.

Complaints, cardiological anamnesis, cardiovascular risk factors, physical examination data, laboratory and instrumental examination, including 12-leads ECG, were analysed. AP was measured three times on both brachial arteries in sitting position, not earlier than 30 minutes after physical exertion, with mean AP (MAP) calculated. Pulse AP (PAP) was measured as difference between systolic AP (SAP) and diastolic AP (dAP). Mean AP (MAP) calculations are: $\mathrm{MAP}=0.42 *(\mathrm{sAP}-\mathrm{dAP})+\mathrm{dAP}$.

Insulin plasma level was measured with Insulin Rapid AccuBind ELISA kits (Monobind Insulin, USA) agents. Serum glucose level was measured with biochemical analyser Flexor E («Vital Scientific N.V.», Netherlands), kit «Glucose SPL» colorimetric method GOD-POD. The homeostatic model assessment index (HOMA-ir) was calculated according to the formula:

fasting insulin (microU/L) × fasting glucose $(\mathrm{nmol} / \mathrm{L}) / 22.5$.

Homa-ir more than 2.5 was pointed as insulin resistence

Serum glycated haemoglobin (HbA1c) was measured with Liquidirect kit (Human GmbH, Germany).

We measured levels of total cholesterol (TC), high density lipoproteins (HDL), low density lipoproteins (LDL) and triglycerides (TG) by fermentative method with automated biochemical photometer Prestige 24 (Japan) with kits PZ CORMAY S.A. (LQ CHOL; LQ TG; HDL DIRECT; LDL DIRECT, Poland) Also we calculate atherogenic index (AI) by the A.M. Klimov formula (1977) [13]: AI=(TC-HDL)/LDL. NT-proBNP was measured with «ELISA kit».

Transthoracic echocardiography (TTE) was performed with SiemensACUSONIC 2000 (SiemensMedicalSolution, Mountain View, USA), phased-array probe 3,5-7 MHz. Were measured: left ventricle end-diastolic volume (LV EDV), left ventricle end-systolic volume (LV ESV), left atrium linear dimension (LALD), left ventricle ejection fraction (LV EF), transmitral deceleration time (Dt), left ventricle isovolumic relaxation time (IVRT), the ratio of peak velocity blood flow in early diastole to peak velocity flow in late diastole E/A ratio, the ratio of transmitral Doppler early filling velocity to tissue Doppler early diastolic mitral annular velocity (E/e'), mean pulmonary artery pressure (PA MP).

We measured endothelium dependent dilation in the brachial arteries (EDD). Degree of EDD was measured by reactive hyperemia, observed by wide-broad linear probe $5-12 \mathrm{MHz}$ in colour doppler mode three times in left and right brachial arteries with 15 minutes interval, method by Celermajer D. S. [14] modified after Ivanova A. V. [15].

Observational period was 12 month after in-hospital treatment.

Standard medication was provided: $\beta$-blocker bisoprolol $-2.5-5 \mathrm{mg}$ at morning, ACE inhibitor ramipril - 5-10 $\mathrm{mg}$ once at evening, amlodipin - 2.5-10 $\mathrm{mg}$ at evening, ASA - $75 \mathrm{mg}$ once after day meal, atorvastatin $20 \mathrm{mg}$ once after day meal, if additional hypotensive therapy needed - indapamid - $2.5 \mathrm{mg}$ once at morning, metformin 100-1500 mg per day.

Statistical analysis was performed with SPSS 19 software for Windows. Quantitative variables are described as median (M), 25 and 75 quartiles (M [Q1; Q3]) qualitative data - as frequency of the events ( $\%$ from normal observations). In order to identify differences between independent samples was used Mann-Whitney U-criteria. Frequency of sign occurrence in groups was compared by $\chi^{2}$ criteria. 


\section{Results}

After 12 months of study, enrolled patients were divided in two groups depending on outcomes. Group I ( $n=66)$ - favourable outcome of IHF, age 60.0 [55.8; 63.3] years, group II ( $n=34)-$ unfavourable outcome, mean age $58.0[55.0 ; 60.3]$ years. There was no statistically significant difference in age ( $>00.05$ ) (Table 1). In group II CHF progressed, that was characterized by LV EF decrease in 13 patients (38\%), diastolic dysfunction in 14 (41\%) patient, death in 7 (20\%) patients.

Duration of IHD varies from 5 to 10 years. Duration of DM type II - from 5 to 9 years. Family history of DM type II had $36.4 \%$ of patients in group I and $58.8 \%$ in group II ( $\mathrm{p}=0.03$ ). Every patient with DM type was in subcompensated state (fasting glucose $<7.6 \mathrm{mmol} / \mathrm{l}$, glycated haemoglobin $<8.0 \%$ ).

During analysis of family and clinical history in both groups, CHF was significantly associated duration of IHD ( $p=0.014)$, and DM type II $(p=0.001)$ Statistically significant difference in IHD family history appearance was not found in both groups $(\mathrm{p}>0.05)$, also as in BMI $(\mathrm{p}>0.05)$ (Table 1).

Table 1

Demography and anamnestic data of patients with IHD in both groups $\left(\mathrm{Me}\left[\mathrm{Q}_{1} ; \mathrm{Q}_{3}\right]\right)$

\begin{tabular}{lccc}
\hline \multicolumn{1}{c}{ Indicator, unit } & Group I, $(\mathbf{n}=\mathbf{6 6})$ & Group II, $(\mathbf{n}=\mathbf{3 4})$ & $\mathbf{p}$ \\
\hline Age, years & $60.0[55.8 ; 63.3]$ & $58.0[55.0 ; 60.3]$ & $>0.05$ \\
IHD present, years & $6.0[5.0 ; 7.0]$ & $7.00[5.0 ; 10.0]$ & 0.014 \\
DM type II present, years & $5.0[5.0 ; 6.0]$ & $6.0[5.0 ; 9.0]$ & 0.001 \\
BMI $\left(\mathrm{kg} / \mathrm{m}^{2}\right)$ & $26.9[26.1 ; 27.9]$ & $25.6[24.8 ; 29.5]$ & $>0.05$ \\
IHD family history, $\%$ & 40.9 & 58.8 & $>0.05$ \\
DM type II family history, $\%$ & 36.4 & 58.8 & 0.03
\end{tabular}

During the analysis of AH level was found that AP from 160/100 to 179/99 $\mathrm{mmHg}$ statistically significant more frequent was found in group I - 71.2 \% vs $47.1 \%(\mathrm{p}=0.03)$, at the same time AP 180/110 mmHg and higher was found more frequent in group II $-52.9 \%$ vs $28.8 \%(p=0.02)$. Physical exertion tolerance, smoking did not differ $(\mathrm{p}>0.05)$ (Table 2).

Table 2

Clinical examination data of patients with IHD and DM type II in both groups

\begin{tabular}{lccc}
\multicolumn{1}{c}{ Indicator, unit } & Group I, $(\mathbf{n}=\mathbf{6 6})$ & Group II, $(\mathbf{n}=\mathbf{3 4})$ & $\mathbf{p}$ \\
\hline Physical exertion: impaired, \% & 80.3 & 91.2 & $>0.05$ \\
Smoking, \% & 72.7 & 82.4 & $>0.05$ \\
AH level: & & & 0.02 \\
- AP from 160/100 to 179/99 $\mathrm{mmHg}, \%$ & 71.2 & 47.1 & 0.02 \\
- AP 180/110 $\mathrm{mmHg}$ and more, $\%$ & 28.8 & 52.9 &
\end{tabular}

In group II values of $\mathrm{sAP}(\mathrm{p}=0.001)$, $\mathrm{pAP}(\mathrm{p}=0.001)$ и $\mathrm{HR}(\mathrm{p}=0.001)$ were statistically significant higher than in group I (Table 3). 6 min walk test had similar results in both groups ( $\mathrm{p}>0.05)$ (Table 3).

Main factor, responsible for atherosclerosis in patient with DM type II is hyperglycaemia. Comparing data in both groups, was found statistically significant higher $\mathrm{HbA1c}(\mathrm{p}=0,001)$, almost twice higher HOMA-ir $(p=0.001)$, fasting glucose $(p=0.004)$, postprandial glucose $(p=0.002)$, insulin level $(\mathrm{p}=0.001)$ in group II (Table 4). 
Table 3

Hemodynamic values, 6 min walk test in patients with IHD and DM type II (Me $\left.\left[Q_{1} ; Q_{3}\right]\right)$

\begin{tabular}{cccc}
\hline Indicator, unit & Group I, $(\mathbf{n}=\mathbf{6 6})$ & Group II, $(\mathbf{n}=\mathbf{3 4})$ & $\mathbf{p}$ \\
\hline sAP, $\mathrm{mmHg}$ & $135.0[130.0 ; 145.0]$ & $145.0[140.0 ; 151.25]$ & 0.001 \\
pAP, mmHg & $50.0[45.0 ; 60.0]$ & $65.0[50.0 ; 75.0]$ & 0.001 \\
HR, min $^{-1}$ & $68.5[65.75 ; 74.0]$ & $75.0[69.5 ; 78.0]$ & 0.001 \\
6 min walk test, $\mathrm{m}$ & $366.5[338.75 ; 389.0]$ & $371.0[355.0 ; 382.5]$ & $>0.05$
\end{tabular}

Table 4

Carbohydrate metabolism characteristics in patients with IHD and DM type II $\left(\mathrm{Me}\left[\mathrm{Q}_{1} ; \mathrm{Q}_{3}\right]\right)$

\begin{tabular}{cccc}
\hline Indicator, unit & Group I, $(\mathbf{n}=\mathbf{6 6})$ & Group II, $(\mathbf{n}=\mathbf{3 4})$ & $\mathbf{p}$ \\
\hline HbAlc, $\%$ & $7.0[6.6 ; 7.2]$ & $7.4[7.8 ; 7.6]$ & 0.001 \\
Fasting glucose, $\mathrm{mmol} / 1$ & $6.05[5.78 ; 6.3]$ & $6.35[5.9 ; 6.9]$ & 0.004 \\
Postprandial glucose, $\mathrm{mmol} / 1$ & $8.4[7.8 ; 8.8]$ & $8.9[8.4 ; 9.2]$ & 0.002 \\
Insulin, mcME/ml & $19.2[15.3 ; 22.6]$ & $29.3[26.8 ; 33.3]$ & 0.001 \\
HOMA-ir & $4.9[4.0 ; 6.4]$ & $8.2[7.3 ; 9.4]$ & 0.001
\end{tabular}

Comparing lipid metabolism values in both groups, statistically significant higher values of TC $(p=0.001)$, LDL $(p=0.001)$, atherogenic index $(p=0.001)$ was found in group II. No difference was found between TG and HDL ( $p>0.05)$ (Table 5).

Table 5

Lipid metabolism characteristics in patients with IHD and DM type II $\left(\mathrm{Me}_{[}\left[\mathrm{Q}_{1} ; \mathrm{Q}_{3}\right]\right)$

\begin{tabular}{cccc}
\hline Indicator, unit & Group I, $(\mathbf{n}=\mathbf{6 6})$ & Group II, $(\mathbf{n}=\mathbf{3 4})$ & $\mathbf{p}$ \\
\hline $\mathrm{TC},(\mathrm{mg} / \mathrm{dl})$ & $233.5[224.5 ; 245.3]$ & $261.0[249.8 ; 277.0]$ & 0.001 \\
$\mathrm{TG},(\mathrm{mg} / \mathrm{dl})$ & $167.5[156.0 ; 183.3]$ & $169.0[148.0 ; 184.3]$ & $>0.05$ \\
$\mathrm{HDL},(\mathrm{mg} / \mathrm{dl})$ & $42.0[41.0 ; 43.0]$ & $42.0[41.0 ; 43.0]$ & $>0.05$ \\
LDL, $(\mathrm{mg} / \mathrm{dl})$ & $159.0[148.6 ; 171.5]$ & $184.2[172.8 ; 197.7]$ & 0.001 \\
AI & $4.6[4.3 ; 4.8]$ & $5.1[4.9 ; 5.7]$ & 0.001
\end{tabular}

In group II ( $n=34)$ compared to group I $(n=66)$ was found significant larger LALD $(p=0.001)$.

LV EF was preserved in both groups, but it was statistically significant lower in group II ( $p=0.001)$

(Table 6).

Table 6

Cardio-vascular ultrasound measurement in patients with IHD and DM type II $\left(\mathrm{Me}_{\mathrm{C}}\left[\mathrm{Q}_{3}\right]\right)$.

\begin{tabular}{cccc}
\hline Indicator & Group I, $(\mathbf{n}=\mathbf{6 6})$ & Group II, $(\mathbf{n}=\mathbf{3 4})$ & P \\
\hline LALD, mm & $35.5[34.8 ; 36.6]$ & $37.2[36.0 ; 38.2]$ & 0.001 \\
EdV, ml & $113.9[106.4 ; 123.8]$ & $115.5[107.3 ; 118.9]$ & $>0.05$ \\
EsV, ml & $39.6[35.0 ; 44.1]$ & $41.9[37.9 ; 45.0]$ & $>0.05$ \\
LV EF, \% & $66.3[64.4 ; 67.6]$ & $62.8[60.8 ; 66.4]$ & 0.001 \\
Dt, sec & $0.24[0.22 ; 0.25]$ & $0.25[0.24 ; 0.26]$ & 0.001 \\
IVRT, sec & $0.13[0.12 ; 0.14]$ & $0.14[0.13 ; 0.14]$ & $>0.05$ \\
E/A ratio & $0.76[0.72 ; 0.78]$ & $0.69[0.64 ; 0.74]$ & 0.001 \\
E/è, ratio. & $7.29[6.95 ; 7.67]$ & $7.38[6.61 ; 7.90]$ & $>0.05$ \\
PA MP, mmHg. & $16.1[14.4 ; 17.7]$ & $17.0[16.0 ; 18.3]$ & 0.003 \\
Brachial arteries EDD, $\%$ & $9.00[8.50 ; 9.60]$ & $6.85[5.48 ; 9.25]$ & 0.001
\end{tabular}


No difference in EsV and EdV was found $(\mathrm{p}>0.05)$. Significantly higher was PA MP $(p=0.003)$ and Dt $(p=0.001)$ in group II. E/A ratio was higher in group I $(p=0.001)$, IVRT and E/e ratio doesn't differ in two groups $(\mathrm{p}>0.05)$.

Brachial arteries EDD was higher in group I ( $p=0.001)$ (Table 6).

Significantly higher level of NT-proBNP was in patients group II - $308.5[210 ; 351.2] \mathrm{pg} / \mathrm{ml}$ compared to the group I - $190[161.5 ; 225.3] \mathrm{pg} / \mathrm{ml}(\mathrm{p}=0.001)$.

\section{Discussion}

HFpEF is a complex clinical condition, both in terms of diagnosis and treatment of this syndrome. In the actual practice of the physician, it is found that patients with HFpEF are receiving the same treatment as patients with HFrEF $[16,17]$. However, if prognosis for RAAS blockers, beta-blockers, or mineralocorticoid receptor antagonists has been shown to improve prognosis for patients with HFpEF, there is no evidence for the efficacy of these drugs in patients with HFpEF [18].

In our study, unfavourable outcome of CHF in patients with CHD and DM type II was associated with higher incidence of CHD and DM duration; also, there was tendency of higher age. In group II rates of DM type II family history, AP level was significantly high, also there was a tendency to higher incidence of CHD family history and lower physical exertion tolerance.

Unfavourable outcome of CHF was associated with more severe lipid and carbohydrate disturbances. Lipid metabolism disturbance leads to severe forms of DM type II that is also demonstrated in another study. A study of the state of lipid metabolism in patients with coronary heart disease and CHF showed in $45.9 \%$ of cases of hypercholesterolemia, in $62 \%$ - increase in low-density lipoprotein, in $15.3 \%$ - decrease in high-density lipoprotein [19].

To date, the possibility of identifying patients who are prone to the progression of LV diastolic dysfunction in CHF is widely discussed in the literature. Early detection of these patients and more careful monitoring can help improve treatment outcomes and develop new treatment options [20, 21].

Even if patients with CHD and DM type II have LV EF preserved (HFpEF), in case of unfavourable outcome EF was significantly lower and was a strong predictor of one. All patients had left ventricle diastolic dysfunction 1 degree, despite normal LALD, but median was higher in group II. DT was higher in group II, that shows more severe diastolic dysfunction degree.

Group II is characterized by higher rate of endothelial dysfunction, which shows severe remodelling processes in vessels.

The coexistence of HFpEF and type 2 diabetes predicts an increased risk of morbidity and mortality. Therefore, there is an increasing need to find new diagnostic tools and treatments to improve clinical outcomes in patients with CHF and type 2 diabetes. Accordingly, it is important for both states to optimize drug therapy and lifestyle while balancing the potential for side effects of medication. Although there are no specific guidelines for the management of patients with HFpEF suffering from diabetes [22].

Limitations of the study. Our study is limited by the number of patients with strict inclusion criteria. This failed to analyse the association of CHD and DM type II in patients with borderline LV EF.

Prospects for further research. Detection of simple predictors of adverse $\mathrm{CH}$ course in patients with CHD and DM type II is an urgent task of modern medicine. Achieving this goal makes it possible to stratify a group of patients with high-risk $\mathrm{CH}$ complications for closer observation. The increase in the number and groups of patients with $\mathrm{CH}$, the duration of follow-up, will help to identify more sensitive predictors of adverse course of pathology.

\section{Conclusions}

Severity of CHF with preserved LV EF in patients with IHD and DM type II is associated with disease duration, $\mathrm{AH}$ level and severity of lipid and carbohydrate metabolism disturbances.

Higher blood level of total low-density lipoproteins, HbAcl, glycemia, index HOMA and atherogenic index was in patients with unfavourable outcome. 
In patients with unfavourable outcome was more low LV EF but in range not lower than $50 \%$ and EDD.

Early markers of unfavourable outcome are increase of dT and increases of PA MP even in range not higher than $20 \mathrm{mmHg}$.

\section{Conflict of interest}

There is no conflict of interest.

\section{References}

[1] Severino, P., D’Amato, A., Netti, L., Pucci, M., De Marchis, M., Palmirotta, R. et. al. (2018). Diabetes Mellitus and Ischemic Heart Disease: The Role of Ion Channels. International Journal of Molecular Sciences, 19 (3), 802. doi: https://doi.org/10.3390/ ijms19030802

[2] IDF Diabetes Atlas (2015). Available at: https://www.idf.org/e-library/epidemiology-research/diabetes-atlas/13-diabetes-atlas-seventh-edition.html

[3] Kumar, R., Kerins, D. M., Walther, T. (2015). Cardiovascular safety of anti-diabetic drugs. European Heart Journal - Cardiovascular Pharmacotherapy, 2 (1), 32-43. doi: http://doi.org/10.1093/ehjcvp/pvv035

[4] Stratton, I. M., Adler, A. I., Neil, H. A. et. al. (2000). Association of glycaemia with macrovascular and microvascular complications of type 2 diabetes (UKPDS 35): prospective observational study. BMJ, 321 (7258), 405-412. doi: http://doi.org/10.1136/ bmj.321.7258.405

[5] Chatterjee, S., Khunti, K., Davies, M. J. (2017). Type 2 diabetes. The Lancet, 389 (10085), 2239-2251. doi: http://doi.org/10.1016/ s0140-6736(17)30058-2

[6] Bowes, C. D., Lien, L. F., Butler, J. (2019). Clinical aspects of heart failure in individuals with diabetes. Diabetologia, 62 (9), 1529-1538. doi: http://doi.org/10.1007/s00125-019-4958-2

[7] Jia, G., Whaley-Connell, A., Sowers, J. R. (2017). Diabetic cardiomyopathy: a hyperglycaemia- and insulin-resistance-induced heart disease. Diabetologia, 61 (1), 21-28. doi: http://doi.org/10.1007/s00125-017-4390-4

[8] Yahagi, K., Kolodgie, F. D., Lutter, C., Mori, H., Romero, M. E., Finn, A. V., Virmani, R. (2017). Pathology of Human Coronary and Carotid Artery Atherosclerosis and Vascular Calcification in Diabetes Mellitus. Arteriosclerosis, Thrombosis, and Vascular Biology, 37 (2), 191-204. doi: http://doi.org/10.1161/atvbaha.116.306256

[9] Saotome, M., Ikoma, T., Hasan, P., Maekawa, Y. (2019). Cardiac Insulin Resistance in Heart Failure: The Role of Mitochondrial Dynamics. International Journal of Molecular Sciences, 20 (14), 3552. doi: http://doi.org/10.3390/ijms20143552

[10] Ponikowski, P., Voors, A. A., Anker, S. D., Bueno, H., Cleland, J. G. F., Coats, A. J. S. et. al. (2016). 2016 ESC Guidelines for the diagnosis and treatment of acute and chronic heart failure. European Heart Journal, 37 (27), 2129-2200. doi: http:// doi.org/10.1093/eurheartj/ehw128

[11] Ponikowski, P., Voors, A. A., Anker, S. D., Bueno, H., Cleland, J. G. F., Coats, A. J. S. et. al. (2016). ESC Guidelines for the diagnosis and treatment of acute and chronic heart failure: The Task Force for the Diagnosis and Treatment of Acute and Chronic Heart Failure of the European Society of Cardiology (ESC). European Heart Journal, 37 (27), 2129-2200. doi: http:// doi.org/10.1093/eurheartj/ehw128 American diabetes association. Standards of Medical Care in Diabetes-2017 (2017). Diabetes Care, 40 (1), 135.

[12] Klimov, A. N. (1977). Prichiny i usloviya razvitiya ateroskleroza. Preventivnaya kardiologiya, 260-321.

[13] Celermajer, D. S., Sorensen, K. E., Gooch, V. M., Spiegelhalter, D. J., Miller, O. I., Sullivan, I. D. et. al. (1992). Non-invasive detection of endothelial dysfunction in children and adults at risk of atherosclerosis. The Lancet, 340 (8828), 1111-1115. doi: http://doi.org/10.1016/0140-6736(92)93147-f

[14] Ivanova, O. V., Rogoza, T. V., Balakhonova, G. N. (1998). Opredelenie chuvstvitelnosti plechevoi arterii k napriazheniiu sdviga na endotelii kak metod ocenki sostoianiia endoteliizavisimoi vazodilatacii s pomoschiu ultrazvuka vysokogo razresheniia $u$ bolnykh s arterialnoi gipertoniei. Kardiologiia, 3, 37-41.

[15] Savarese, G., Lund, L. H. (2017). Global Public Health Burden of Heart Failure. Cardiac Failure Review, 3 (1), 7-11. doi: http:// doi.org/10.15420/cfr.2016:25:2

[16] Braunwald, E. (2015). The war against heart failure: the Lancet lecture. The Lancet, 385 (9970), 812-824. doi: http://doi.org/ 10.1016/s0140-6736(14)61889-4

[17] Cleland, J. G. F., Bunting, K. V., Flather, M. D., Altman, D. G., Holmes, J. et. al. (2017). Beta-blockers for heart failure with reduced, mid-range, and preserved ejection fraction: an individual patient-level analysis of double-blind randomized trials. European Heart Journal, 39 (1), 26-35. doi: http://doi.org/10.1093/eurheartj/ehx564 
[18] Udell, J. A., Cavender, M. A., Bhatt, D. L., Chatterjee, S., Farkouh, M. E., Scirica, B. M. (2015). Glucose-lowering drugs or strategies and cardiovascular outcomes in patients with or at risk for type 2 diabetes: a meta-analysis of randomised controlled trials. The Lancet Diabetes \& Endocrinology, 3 (5), 356-366. doi: http://doi.org/10.1016/s2213-8587(15)00044-3

[19] Lam, C. S. (2015). Diabetic cardiomyopathy: An expression of stage B heart failure with preserved ejection fraction. Diabetes and Vascular Disease Research, 12 (4), 234-238. doi: http://doi.org/10.1177/1479164115579006

[20] Lehrke, M., Marx, N. (2017). Diabetes Mellitus and Heart Failure. The American Journal of Medicine, 130 (6), S40-S50. doi: http://doi.org/10.1016/j.amjmed.2017.04.010

[21] Cosentino, F., Grant, P. J., Aboyans, V., Bailey, C. J., Ceriello, A., Delgado, V. et. al. (2019). 2019 ESC Guidelines on diabetes, pre-diabetes, and cardiovascular diseases developed in collaboration with the EASD. European Heart Journal, 41 (2), $255-323$. doi: http://doi.org/10.1093/eurheartj/ehz486

\title{
ST2 PLASMA LEVEL IN PATIENTS WITH ACUTE MYOCARDIAL INFARCTION WITHOUT ST ELEVATION AND DIFFERENT CLINICAL CHARACTERISTICS
}

\author{
Iryna Mezhiievska \\ irinamezhiievska@gmail.com \\ Valerii Ivanov $^{1}$ \\ Valentyn Maslovskyi ${ }^{1}$ \\ ${ }^{1}$ Department of Internal Medicine No. 3 \\ National Pirogov Memorial Medical University \\ 56 Pirogova str., Vinnytsya, Ukraine, 21018
}

\begin{abstract}
The aim. Estimation of ST2 plasma level in patients with acute myocardial infarction without ST elevation (NSTEMI) and its relationship with different clinical characteristics.

Materials and methods. 165 patients aged from 35 to 79 (average of $60.7 \pm 0.8$ years) with various forms of coronary artery disease (CAD) with and without arterial hypertension were examined. The variability of plasma ST2 level in different forms of CAD and in NSTEMI group was analyzed depending on gender-age and clinical characteristics and features of the disease course.

\section{Results:}

The results of the present investigation were that the ST2 level in the main cohort was in range from 5.5 to 233.9 (in the middle $-49.8 \pm 3.5 \mathrm{ng} / \mathrm{ml}$ (median indicator -34.7 and the interquartile range -21.9 and 59.1 respectively).

Significantly higher ST2 levels were found in patients with NSTEMI, unlike the comparison group, in the median analysis ( 35.9 vs. $27.7 \mathrm{ng} / \mathrm{ml}, \mathrm{p}=0.047$ ) and no statistical differences were observed in the mean values.

In patients with NSTEMI, a certain association of ST2 level in plasma with the MI course was detected. A higher level of neurohormone is registered with anterior unlike posterior ECG localization of MI; at high unlike moderate risk on the GRACE scale; when complicated unlike the uncomplicated course of MI; in the case of acute HF and cardiac arrhythmias unlike patients with the absence of these manifestations in the acute period of MI.

Conclusions. High variability of ST2 level in plasma was demonstrated in patients with NSTEMI on the first day after destabilization (minimum and maximum values -12.7 and 233.9 respectively, median - 35.9 and interquartile range $-25.9 \mathrm{and} 55.7 \mathrm{ng} / \mathrm{ml}$ ).

It is shown that significantly higher ST2 level in plasma is determined in patients with acute MI regardless of its variant among different clinical forms of CAD.

It is found that significantly higher level of ST2 in patients with NSTEMI is recorded in the case of concomitant HTN and type 2 diabetes, with smoking and heavy cardiovascular heredity. Proved influence of the character of MI course on the level of ST2
\end{abstract}

